\title{
How Hospital Pharmacists Spend Their Time: A Work-Sampling Study
}

\author{
Daniel Wong, Andrea Feere, Vandad Yousefi, Nilufar Partovi, and Karen Dahri
}

Can J Hosp Pharm. 2020;73(4):272-8

\begin{abstract}
Background: The expanded scope of pharmacist practice allows for increased comprehensive care and improved patient outcomes at the cost of increased workload and time demands on pharmacists. There are limited descriptive metrics for the time that pharmacists spend on various activities during the workday. An evaluation of the time spent on different activities would allow for potential optimization of workflow, with a focus primarily on devoting more time to direct patient care activities.
\end{abstract}

Objective: To quantify the amount of time that hospital and clinicbased pharmacists spend on clinical activities, including direct and indirect patient care, and nonclinical activities.

Methods: An observational fixed-interval, work-sampling study was conducted at 2 hospitals, Vancouver General Hospital and Richmond Hospital, both in British Columbia. Trained observers followed individual pharmacists for a set period. The pharmacists' activities were recorded in 1-min increments and classified into various categories.

Results: In total, 2044 min of activity, involving 11 individual pharmacists, were observed. Clinical activities accounted for $82 \%$ of total time, 12\% (251 min) on direct patient care activities and 70\% (1434 min) on indirect patient care activities. The most common direct clinical activity was conducting patient medication history interviews (73 min; $4 \%$ of total time), and the most common indirect clinical activity was assessment and evaluation (585 min; 29\%). The most common nonclinical activities were walking (91 min; $4 \%$ of total time), looking for something (57 min; 3\%), and teaching pharmacy students on practicum (60 $\min ; 3 \%)$.

Conclusions: Although the pharmacists spent most of their time on clinical activities, face-to-face time with patients (direct clinical activities) seemed low, which highlights an area for potential improvement. The pharmacists spent much more time documenting information in pharmacy-specific monitoring forms (i.e., assessment and evaluation) than they spent writing notes or recommendations in the chart, for sharing with other health care professionals.

Keywords: time, work sampling, pharmacist, activities

\section{RÉSUMÉ}

Contexte : L'élargissement du champ d'activité du pharmacien permet d'améliorer la qualité des soins et les résultats pour le patient au prix d'une augmentation de la charge et du temps de travail des pharmaciens. Il existe peu de mesures descriptives temps que les pharmaciens consacrent à leurs diverses activités de la journée. Une évaluation de ce temps permettrait d'optimiser le flux de travail afin que l'accent puisse être mis principalement sur l'augmentation du temps réservé aux activités de soins directs des patients.

Objectif : Quantifier le temps que passent les pharmaciens des hôpitaux et des cliniques à effectuer des activités cliniques, y compris des activités de soins directs et indirects, ainsi que des activités non cliniques.

Méthodes : Une étude observationnelle par échantillonnage à intervalles fixes a été menée dans deux hôpitaux : le Vancouver General Hospital et le Richmond Hospital, tous deux en Colombie-Britannique. Des observateurs formés ont suivi chaque pharmacien en particulier pendant une période déterminée. Leurs activités étaient consignées par tranches d'une minute et classées en diverses catégories.

Résultats : L'observation a porté sur des activités totalisant 2044 minutes réparties entre 11 pharmaciens. Les activités cliniques représentaient $82 \%$ du temps total, $12 \%$ (251 min) des activités étaient consacrées aux soins directs et $70 \%$ (1434 min), aux soins indirects. L'activité clinique directe la plus courante consistait à mener des entrevues portant sur les antécédents pharmacothérapeutiques des patients (73 min, $4 \%$ du temps total) et I'activité clinique indirecte la plus courante était l'évaluation (585 min, $29 \%$ ). Les activités non cliniques les plus courantes étaient la marche (91 min, $4 \%$ du temps total), la recherche de quelque chose (57 min, $3 \%$ ) et la formation des étudiants stagiaires en pharmacie (60 min, $3 \%$ ).

Conclusions : Bien que les pharmaciens consacrent la plus grande partie de leur temps à des activités cliniques, le temps passé auprès des patients (activités cliniques directes) semblait faible, ce qui indique une possibilité d'amélioration. Les pharmaciens passent beaucoup plus de temps à consigner de l'information dans des formulaires de contrôle spécifiques à la pharmacie (c.-à-d. évaluation) qu'à rédiger des notes ou des recommandations dans les tableaux pour les partager avec les autres professionnels de la santé.

Mots-clés : temps, échantillon de travail, pharmacien, activités 


\section{INTRODUCTION}

In the inpatient setting, pharmacist-initiated interventions have been associated with reductions in adverse drug events, improvements in medication adherence, and shortened hospital stays. ${ }^{1}$ Since 2009 , legislative changes at the federal and provincial levels have given rise to an expanded scope of practice for pharmacists in Canada. ${ }^{2}$ As a result, pharmacists in both hospital and community settings are developing a more immersive role within the health care team and are now able to change drug dosages, make therapeutic substitutions, administer vaccines, order laboratory tests and evaluate their results, and initiate drug therapy. ${ }^{2-5}$ This expanded scope of practice has resulted in improved patient outcomes, increased pharmacist job satisfaction (secondary to increased autonomy), and reduced health care costs. ${ }^{5}$ However, the expansion of pharmacy practice has also increased demands on pharmacists' time. A survey evaluating the impact of expanded practice on hospitalbased pharmacists in a single Canadian centre found that although these pharmacists were able to increase comprehensive patient care, they felt that lack of time was the greatest barrier to maximizing their expanded roles. ${ }^{3,5}$ Evaluating how hospital pharmacists spend their time during the workday may allow identification of areas for increased efficiency.

Observational studies in Australia have previously evaluated how hospital-based pharmacists spend their working day. Investigators shadowed pharmacists to see what tasks they performed daily and to determine approximately how much time was spent on each task. ${ }^{6-8}$ For example, deClifford and others ${ }^{6}$ looked at the amount of time hospital pharmacists spent performing clinical and nonclinical activities to gather baseline data on the pharmacists' tasks. They found that $56 \%$ of total time was devoted to clinical activities, with the bulk of this time being spent on professional communication, chart reviews, and medication history interviews. Time spent on nonclinical activities included breaks, social activities, ordering drugs, and discharge dispensing. Similar results were observed in a time-sampling study comparing pharmacist productivity on wards with and without electronic medication management systems. ${ }^{7}$ Medication chart review was the most frequently performed activity (35\% and $36 \%$ of observed time, respectively, on wards with and without the electronic systems), followed by clinical review ( $18 \%$ and $14 \%$, respectively). ${ }^{7}$ Stuchbery and others ${ }^{8}$ obtained different results when they recorded the activities of 6 clinical pharmacists over 3 days. They noted that medication order review was the most frequently recorded event $(53.7 \%$ of total events), which suggested a greater emphasis on dispensaryrelated tasks. ${ }^{8}$

These divergent results suggest that a pharmacist's workday may be influenced by site-specific demands; however, differences in the definitions of clinical and nonclinical activities in previous studies may also account for the observed variation in results. Therefore, it is difficult to predict how these findings would apply to the work distribution of pharmacists practising at sites in Canada, or British Columbia specifically.

The objective of this observational study was to develop a better understanding of how hospital and clinic-based pharmacists spend their time, using a work-sampling methodology. To our knowledge, no such studies have been conducted to describe the work distribution of pharmacists in Canadian hospitals. By gaining a clearer sense of how much time is spent performing different activities, we aimed to obtain insights into whether efficiencies can be found to optimize pharmacists' utilization of their time.

\section{METHODS}

\section{Design and Sampling}

In this observational study, a fixed-interval, work-sampling methodology was used to assess the workflow of hospital and clinic-based pharmacists in 2 acute care institutions in British Columbia, Canada-Vancouver General Hospital and Richmond Hospital-over a 6-month period (March to August 2017). A similar approach has previously been used to study the workflow of other health care providers. ${ }^{6-9}$ Vancouver General Hospital is a tertiary care centre with a staff that includes 50 pharmacists working on wards or clinics on any given day, whereas Richmond Hospital is a smaller community hospital, with 7 pharmacists working on wards or clinics daily. The pharmacists at both hospitals cover a variety of inpatient, outpatient, and critical care settings. Pharmacists may be employed in positions that are either entirely focused on the ward or clinic or entirely focused on dispensary duties, or their positions may involve a combination of both types of work.

These 2 hospitals, including their associated outpatient clinics, utilize a combination of electronic and paper-based documentation systems. The electronic computer system contains information about patient medications, laboratory values, diagnostic investigations, and physicians' transcriptions. The paper charts contain daily assessments and progress notes from physicians and the allied health team.

For this study, and more generally in the hospitals involved, clinical work was defined in accordance with the American College of Clinical Pharmacy's Standards of Practice for Clinical Pharmacists. ${ }^{10}$ These standards of practice state that clinical pharmacists possess "accredited residency training or equivalent postlicensure experience" and perform medication management in team-based direct patient care environments. ${ }^{10}$ Pharmacists working primarily in the dispensary, pharmacy assistants, and regulated pharmacy technicians who had limited clinical encounters with patients were therefore excluded. To focus on pharmacists working in clinical rather than dispensary roles, 
pharmacists were observed only when they were scheduled for clinical shifts, such as providing direct patient care on inpatient units or in outpatient clinics.

A literature search was conducted to determine the various activities that could be captured through data collection. ${ }^{6,8}$ The observable activities were categorized as clinical and nonclinical activities. Clinical activities were defined as any activities related to the clinical care of a patient, whereas nonclinical patient care activities were defined as activities with no relation to clinical care. ${ }^{6,8}$ Ten major clinical activities were included, 4 classified as direct patient care activities and 6 classified as indirect patient care activities. In addition, there were 11 major nonclinical activities. The classification system is summarized in Box 1 .

An e-mail invitation to participate in the study was sent out by the administrative staff at each site using group e-mail lists. In addition, an informational presentation was given at each site's monthly pharmacist staff meeting to recruit participants. Pharmacists could directly contact one of the investigators to enrol in the study. Ethics approval was obtained from the University of British Columbia Research Ethics Board, and all participants provided written informed consent.

No honorarium was given to the participants. At the time of enrolment, participants could indicate their preference for when the data collector would shadow them during a regular work shift. To prevent changes in work performance in the context of the study, only the observers (data collectors) had access to individual pharmacists' data. This was intended to maintain blinding and anonymity to other study investigators, who might be in a supervisory role in relation to the pharmacist participants.

\section{Data Collection and Procedure}

Pharmacists' activities were identified and recorded by 1 of 2 trained observers (D.W. or A.F.). Participating pharmacists chose the time and duration of observation during a single 8-h shift. The observers were third-year pharmacy students not employed by the hospitals. These observers completed a training session and a 1-h trial session together to become familiar with the activities performed by pharmacists, so that they could recognize and classify them according to the predetermined categories.

Using a 5E901 Ironman Triathlon watch (Timex), an observer recorded a participant's current activity on a paper activity log every minute, according to the predetermined categories and subcategories. If multiple tasks were performed within the same 1-min interval, the observer noted all tasks, but the task performed for most of the interval was used for data analysis. However, when participants spent more than 1 min performing different activities ("multitasking"), the activities were recorded in an alternating manner every minute until the multitasking ended. This approach was applied consistently to ensure equal representation
BOX 1. Categories of Activities Performed by Hospital Pharmacists

\section{Clinical Activities}

Direct

Patient medication history interview

Patient general interview

Patient medication counselling

Specific drug product

Discharge medications

Contacting other sources of information (family physician, patient's relatives) for collateral information

Indirect

Assessment and evaluation

Review of patient chart

Review of computer system

Patient care rounds

Bedside rounds

Paper rounds/"running the list" (medical team does a quick paper review of each patient's chart)

Interdisciplinary rounds

Therapeutic interventions

Direct recommendations (speaking with physician)

Chart notes for recommendations

Chart notes for documentation

Discharge coordination

Writing discharge prescriptions, medication reconciliation on discharge

Faxing prescriptions

Obtaining health insurance coverage

Pharmacare enrolment

Special Authority approval

Dispensing

Order entry and verification

Checking/labelling product

Communication with staff

Answering questions from ward staff

Answering questions from physicians

Returning pages, answering phone calls

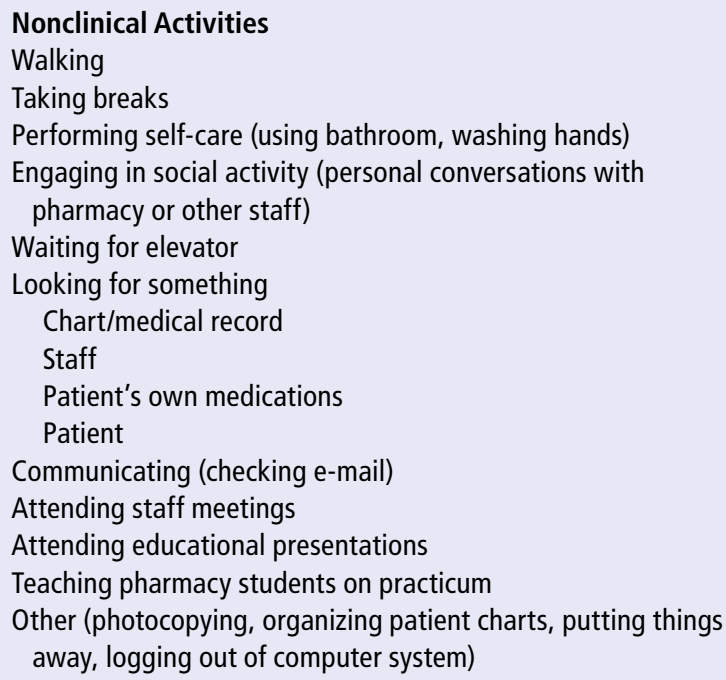

of all activities performed simultaneously, while adhering to the once-per-minute observation protocol. If the 
participant was speaking to other hospital staff, patients, or visitors in a situation requiring confidentiality, the observer waited at an appropriate distance and confirmed the nature of the activity afterward. In the event that the participant took a break during the observation period, only the start and end times of the break were noted. Time that the participant spent talking to the observer or introducing others to the observer was excluded from the analysis.

For instances where pharmacists participated in activities that did not fall within the predefined categories, the observers met after completion of all data collection to determine where to allocate any uncategorized minutes or whether it was necessary to create a new category. If the 2 observers could not reach an agreement, then they consulted one of the study investigators to reach a decision.

\section{Data Analysis}

All recorded activities were transferred to a digital spreadsheet (Microsoft Excel 2015, version 15.0, Microsoft Corporation). Simple descriptive statistics were then applied to determine which activities were performed most frequently and which activities consumed the most time for the pharmacists collectively.

\section{RESULTS}

The observers shadowed the participating pharmacists for a range of 1.5 to 4 consecutive hours in a 1:1 ratio. Data for a total of $2044 \mathrm{~min}(34.1 \mathrm{~h})$ of activity were collected from 11 pharmacists: 1724 min (84\%) from 8 pharmacists at Vancouver General Hospital and 320 min (16\%) from 3 pharmacists at Richmond Hospital. These pharmacists worked in various areas of the hospitals: 4 in inpatient units, 3 in outpatient clinics, and 4 in critical care areas. All of the participating pharmacists had previously completed a hospital pharmacy residency, and 4 pharmacists had also completed a postgraduate Doctor of Pharmacy degree. Each participant was observed on average for $186 \mathrm{~min}$ (standard deviation $59 \mathrm{~min}$ ) over a single uninterrupted observation period. Overall, $82 \%$ of the total time ( $1685 \mathrm{~min})$ was spent doing clinical activities and 18\% of the total time (359 min) was spent on nonclinical activities. Tables 1 and 2 show the breakdown of total time spent performing each type of activity (by category and subcategory).

\section{Clinical Activities}

The time spent performing clinical activities consisted of $251 \mathrm{~min}$ (12\% of total time) for direct clinical activities and $1434 \mathrm{~min}$ (70\% of total time) for indirect clinical activities. The most frequently observed indirect clinical activity, which was also the most frequently observed activity overall, was assessment and evaluation (585 min; 29\% of total time). Participants spent most of that time reviewing various documents on the computer system (380 min; 19\%), which involved activities such as assessing patients' current and past medications, accessing patient information, interpreting laboratory test results, and looking up drug information. Reviewing charts accounted for the remaining time spent on assessment and evaluation (205 min; 10\%), and was often done while simultaneously reviewing other patient information on the computer system. It was also noted that during assessment and evaluation, participants frequently wrote notes in their own pharmacy-specific patient monitoring forms. Participants also spent a

TABLE 1. Time Spent by Hospital Pharmacists on Clinical Activities

\begin{tabular}{|c|c|c|}
\hline \multirow{2}{*}{$\begin{array}{l}\text { Clinical Activity } \\
\text { Direct }\end{array}$} & \multicolumn{2}{|c|}{$\begin{array}{l}\text { Amount }(\%) \\
\text { of Time }(\mathrm{min}) \\
(n=2044)\end{array}$} \\
\hline & 251 & (12) \\
\hline Patient medication history interview & 73 & (4) \\
\hline Patient general interview & 62 & (3) \\
\hline Patient medication counselling & 65 & (3) \\
\hline Specific drug product & 59 & (3) \\
\hline Discharge medications & 6 & $(0.3)$ \\
\hline $\begin{array}{l}\text { Contacting other sources of information (family } \\
\text { physician, patient's relatives) for collateral information }\end{array}$ & 51 & (2) \\
\hline Indirect & 1434 & (70) \\
\hline Assessment and evaluation & 585 & (29) \\
\hline Review of patient chart & 205 & (10) \\
\hline Review of computer system & 380 & (19) \\
\hline Patient care rounds & 466 & (23) \\
\hline Bedside rounds & 258 & (13) \\
\hline Paper rounds/"running the list" & 208 & (10) \\
\hline Interdisciplinary rounds & 0 & $(0)$ \\
\hline Therapeutic interventions & 190 & (9) \\
\hline Direct recommendations (speaking with physician) & 25 & (1) \\
\hline Chart notes for recommendations & 65 & (3) \\
\hline Chart notes for documentation & 100 & (5) \\
\hline Discharge coordination & 61 & (3) \\
\hline $\begin{array}{l}\text { Writing discharge prescriptions, medication } \\
\text { reconciliation on discharge }\end{array}$ & 35 & (2) \\
\hline Faxing prescriptions & 9 & $(0.4)$ \\
\hline $\begin{array}{l}\text { Obtaining health insurance coverage: Pharmacare } \\
\text { enrolment }\end{array}$ & 3 & $(0.1)$ \\
\hline $\begin{array}{l}\text { Obtaining health insurance coverage: Special } \\
\text { Authority approval }\end{array}$ & 14 & (1) \\
\hline Dispensing & 10 & $(0.5)$ \\
\hline Order entry and verification & 8 & $(0.4)$ \\
\hline Checking/labelling product & 2 & $(0.1)$ \\
\hline Communicating with staff & 122 & (6) \\
\hline Answering questions from ward staff & 72 & (4) \\
\hline Answering questions from physicians & 27 & (1) \\
\hline Returning pages, answering phone calls & 23 & (1) \\
\hline
\end{tabular}


substantial proportion of their time attending patient care rounds (466 min; 23\%), which consisted of bedside rounds (258 $\mathrm{min} ; 13 \%$ ) and paper rounds (208 min; 10\%). Participants spent $9 \%$ (190 min) of total time making therapeutic interventions, such as documenting clinical notes in patient charts (100 min; 5\%).

\section{Nonclinical Activities}

The most time-consuming nonclinical activities were walking and looking for things; however, these activities accounted for only $4 \%$ (91 $\mathrm{min}$ ) and 3\% (57 $\mathrm{min}$ ) of total time, respectively. When participants were looking for things, it was most often a patient chart that was being sought (38 min; $2 \%$ ). Participants spent $5 \%$ of their overall time participating in educational activities, such as attending presentations (47 min; $2 \%$ ) and teaching students on practicum (60 min; 3\%). Breaks and checking e-mails accounted for $2 \%$ (39 min) and $1 \%$ (21 min) of participants' total time, respectively.

\section{Post Hoc Analysis of Inpatient and Outpatient Pharmacists}

A subset of the participants $(n=3)$ were identified as working in outpatient units. We therefore conducted a post hoc analysis to determine if there were any differences in clinical activity levels between the inpatient and outpatient

TABLE 2. Time Spent by Hospital Pharmacists on Nonclinical Activities

\begin{tabular}{|lrrr}
\hline Nonclinical Activity & $\begin{array}{r}\text { Amount (\%) } \\
\text { of Time (min) } \\
(\boldsymbol{n}=2044)\end{array}$ \\
\hline All & 359 & $(18)$ \\
\hline Walking & 91 & $(4)$ \\
\hline Taking breaks & 39 & $(2)$ \\
\hline Performing self-care (using bathroom, & 18 & $(1)$ \\
washing hands) & & \\
\hline Engaging in social activity (personal conversations) & 13 & $(1)$ \\
\hline Waiting for elevator & 6 & $(0.3)$ \\
\hline Looking for something & 57 & $(3)$ \\
\hline Chart/medical record & 38 & $(2)$ \\
\hline Staff & 4 & $(0.2)$ \\
\hline Patient's own medications & 0 & $(0)$ \\
\hline Patient & 15 & $(1)$ \\
\hline Communicating (checking e-mail) & 21 & $(1)$ \\
\hline Attending staff meetings & 0 & $(0)$ \\
\hline Attending educational presentations & 47 & $(2)$ \\
\hline Teaching students on practicum & 60 & $(3)$ \\
\hline Other & 7 & $(0.3)$ \\
\hline
\end{tabular}

*Photocopying, organizing charts, putting things away, logging out of the computer system. environments. A total of 1513 min of activity were observed in inpatient units compared with 531 min of activity in outpatient units. Inpatient pharmacists spent $85 \%$ (1291 min) of inpatient time on clinical activities, whereas outpatient pharmacists spent $74 \%$ (394 min) of outpatient time on clinical activities. However, within the clinical activity category, the outpatient pharmacists spent $28 \%$ (147 min) of their total time on direct clinical activities, namely counselling about drug products and conducting general interviews with patients. In contrast, the inpatient pharmacists spent only $7 \%$ (104 min) of their total time on direct clinical activities. The inpatient pharmacists spent most of their clinical time on indirect activities, such as reviewing patient charts and the computer system.

\section{DISCUSSION}

The purpose of this study was to quantify the amount of time that hospital pharmacists spent on various activities and to determine if there are any efficiencies that could be introduced to hospital practice to allow pharmacists to perform more clinical activities rather than nonclinical activities. Our findings suggest that the pharmacists already spend considerably more time performing clinical activities than nonclinical activities ( $82 \%$ versus $18 \%$ ), especially relative to other time-sampling studies. ${ }^{6}$ For example, in their time-sampling study in Australia, deClifford and others ${ }^{6}$ found that hospital pharmacists participated in clinical activities $56 \%$ of the time, leaving $44 \%$ for nonclinical activities.

Despite the large proportion of time spent on clinical activities, we found that only $12 \%$ of total time was spent on direct clinical activities, that is, activities involving direct interactions with patients or caregivers. As valued members of the patient care team, with a rapidly evolving role, pharmacists may have a greater impact by spending more time collaborating with the team and interacting with patients. Regardless of how the role of pharmacists evolves, time spent working directly with patients should remain a priority. Not only might this improve patients' awareness of the role of hospital pharmacists, but it might also increase pharmacists' contributions to the team in areas such as educating patients about their medications, optimizing therapy for efficacy, and minimizing adverse effects of medications. As professionals with highly drug-focused education, pharmacists may gather information and monitor specific parameters that might not have been considered by others. For example, when taking a medication history, a pharmacist may probe into the specifics of a drug interaction, adverse drug reaction, or drug allergy that might not be as thoroughly investigated by others, whether because of lack of time or different priorities. We believe that this is a mechanism whereby increased face-to-face time with patients may yield more discoveries of information that could significantly affect prescribing decisions. 
We also found that pharmacists spent a considerable amount of time (29\%) on assessment and evaluation: copying laboratory values, medication details, drug levels, and other information from the computer system and paper chart into a pharmacy-specific patient monitoring form used by pharmacy staff for patient follow-up. In comparison, only $8 \%$ of total time was spent writing chart notes to share recommendations or documentation with physicians and other health care professionals. It might be beneficial for other health care professionals if pharmacists could allocate more time to documenting their clinical findings and interventions in the patient's permanent health care record rather than the department's own monitoring form. By doing so, pharmacists could showcase their unique assessments with other members of the health care team, providing input for future clinical decisions and documenting their work for others to see.

Pharmacy technicians may also be of great utility in optimizing the workload of pharmacists. For example, they may be in the best position to assist pharmacists by reorganizing and preparing patient charts before pharmacists begin to review patients and before rounds. Nearly one-third of pharmacists' time was spent assessing patient charts and the online system and recording their own notes (i.e., assessment and evaluation), but technicians could accelerate this routine process by compiling all relevant photocopies and print-outs of pertinent resources for a given patient in one folder. Pharmacists would then have access to all required documentation in one location and might therefore be able to allocate more time to working directly with patients and the medical team.

When the existing paper chart system eventually transitions to an electronic system, pharmacists will have direct access to all of the patient information that is currently contained in a mix of paper-based and electronic charting systems. Lo and others ${ }^{7}$ found that the average amount of time required for completing review activities (e.g., medication chart, clinical data, pathology results) was significantly reduced when pharmacists employed electronic medication management systems on the ward. It might therefore be fruitful to repeat a work-sampling study after implementation to assess whether there are any changes in direct clinical activities in these 2 Canadian hospitals.

Although our subanalysis comparing outpatient and inpatient pharmacists involved small sample sizes, it highlighted a notable difference in the type of work that these pharmacists perform daily. As might have been expected, the outpatient pharmacists spent much more time on direct clinical activities than their inpatient counterparts. Interestingly, the inpatient pharmacists spent a large amount of time on indirect clinical activities, which suggests that these participants were driving the numbers in the overall results. However, given the small and uneven amount of data comparing inpatient and outpatient pharmacists, the information is only hypothesis-generating. A larger comparative study is needed to better understand how workflow differs between these different areas of practice.

Despite the use of established methodology for conducting time-sampling studies, there were some limitations to this study. Because of the relatively small sample size, it is difficult to generalize our findings to hospital pharmacy practice more generally. Having an observer constantly present did not allow for a true naturalistic observation of the pharmacists. Additionally, to increase participation, pharmacists were allowed to select a scheduled time at their own convenience for shadowing and observation. This may have skewed our sample to feature more clinical activities. We likely did not capture all of the time that pharmacists spent on breaks and at staff meetings because we observed only a portion of each participant's day. Only one of the pharmacists who participated in the study was serving as a preceptor for a pharmacy student on rotation, so our data are likely not reflective of how much time pharmacists actually spend teaching. For future time-sampling studies, it is recommended that each pharmacist be observed for the entirety of one shift to accurately gauge the various activities performed from the beginning to the end of the shift. Perhaps one contributing reason why deClifford and others ${ }^{6}$ found that pharmacists spent only $56 \%$ of their time on clinical activities was that they observed pharmacists over entire working days. The $56 \%$ value would equate to nearly $4 \mathrm{~h}$ of clinical activities, assuming an 8 -h shift with a 60 -min lunch break. If we theoretically factor a $60-\mathrm{min}$ break into our results and assume the same proportion of clinical activities during the working hours, we would expect to see approximately $5 \mathrm{~h}$ and $45 \mathrm{~min}$ spent on clinical activities per 8-h shift, which would reduce the proportion of clinical activities from $82 \%$ to $72 \%$. Finally, we noted that minimal time was allocated to walking and looking for things, but this may be attributed to the location-based staffing system in the hospitals studied. In other hospitals where staff coverage is more dispersed, more time may be spent on these activities.

\section{CONCLUSION}

This study revealed that pharmacists already spend a significant amount of time performing clinical activities, although most of that time was devoted to indirect clinical activities. It would be worthwhile for future studies to investigate the proportion of time spent in face-to-face interactions between pharmacists and patients, and to observe a larger sample of hospital pharmacists, perhaps through the inclusion of more hospitals. As pharmacy practice continues to evolve, such studies may further illuminate where pharmacists' time is being spent and could be used to determine how to maintain the current emphasis on direct patient care activities over indirect activities. 


\section{References}

1. Kaboli P, Hoth A, McClimon B, Schnipper J. Clinical pharmacists and inpatient medical care. Arch Intern Med. 2006;166(9):955-64.

2. Tannenbaum C, Tsuyuki RT. The expanding scope of pharmacists practice: implications for physicians. CMAJ. 2013;185(14):1228-32.

3. Perreault M. What will makehospital pharmacists successfulas they take on an expanded scope of practice? [editorial]. Can J Hosp Pharm. 2013; 66(5):276-7.

4. Dinh T, Stonebridge C, Brichta J. A review of pharmacy services in Canada and the health and economic evidence. Canadian Pharmacists Association; 2016 [cited 2018 Nov 27]. Available from: https://www. pharmacists.ca/cpha-ca/assets/File/cpha-on-the-issues/Pharmacy\% 20Services\%20Report\%201.pdf

5. Hwang S, Koleba T, Mabasa V. Assessing the impact of an expanded scope of practice for pharmacists at a community hospital. Can J Hosp Pharm. 2013;66(5):304-9.

6. deClifford J, Blewitt P, Lam SS, Leung BK. How do clinical pharmacists spend their working day? A time-and-motion study. J Pharm Pract Res. 2012;42(2):134-9.

7. Lo C, Burke R, Westbrook JI. Electronic medication management systems' influence on hospital pharmacists' work patterns. J Pharm Pract Res. 2010;40(2):106-10.

8. Stuchbery P, Kong DCM, Desantis GN, Lo SK. Identification by observation of clinical pharmacists' activites in a hospital inpatient setting. Pharm Pract. 2007;5(1):10-6.

9. Yousefi V. How Canadian hospitalists spend their time - a worksampling study within a hospital medicine program in Ontario. J Clin Outcomes Manage. 2011;4(18):159-64.

10. American College of Clinical Pharmacy. Standards of practice for clinical pharmacists. Pharmacotherapy. 2014:34(8):794-7.
Daniel Wong, BSc(Pharm), ACPR, is a Clinical Pharmacist with the Royal Columbian Hospital, New Westminster, British Columbia.

Andrea Feere, BSc(Pharm), ACPR, is a Clinical Pharmacist with the Abbotsford Regional Hospital and Cancer Centre, Abbotsford, British Columbia.

Vandad Yousefi, MD, CCFP FHM, is a Hospitalist with the Vancouver General Hospital, Vancouver, British Columbia.

Nilufar Partovi, BSc(Pharm), PharmD, FCSHP, is Coordinator of Clinical Pharmacy Services with the Vancouver General Hospital, University of British Columbia Hospital, and the G F Strong Rehabilitation Centre and is also a Clinical Professor with the Faculty of Pharmaceutical Sciences, The University of British Columbia, Vancouver, British Columbia.

Karen Dahri, BSC(Pharm), ACPR, PharmD, FCSHP is a Clinical

Pharmacotherapeutic and Research Specialist with the Vancouver General Hospital and Assistant Professor (Partner) with the Faculty of Pharmaceutical Sciences, The University of British Columbia, Vancouver, British Columbia.

Competing interests: None declared.

\section{Address correspondence to:}

Dr Karen Dahri

Vancouver General Hospital

855 West 12th Avenue

Vancouver BC V5Z $1 \mathrm{M} 9$

e-mail: Karen.Dahri@vch.ca

Funding: None received.

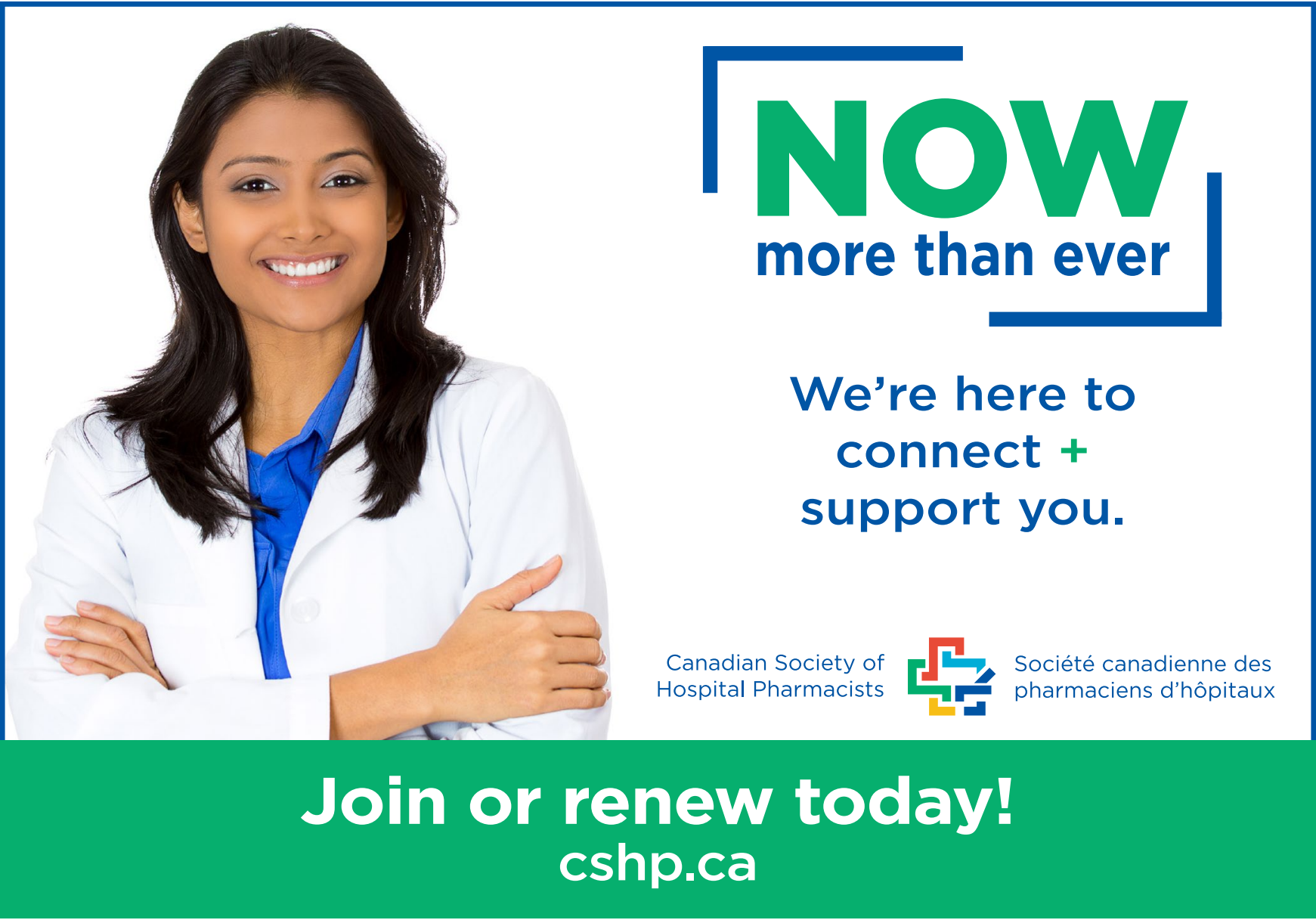

